\title{
Effects of salinity on solid particle settling velocity in non-Newtonian Herschel-Bulkley fluids
}

\author{
Robert Moukhametov ${ }^{1} \cdot$ Anurag Srivastava $^{1} \cdot$ Syeda Akhter $^{1}$. Jerahmeel Bautista ${ }^{1} \cdot$ Hicham Ferroudji ${ }^{1}$ \\ Hassan Hadear ${ }^{1}$. Ibrahim Hassan ${ }^{1}$. Mohammad Azizur Rahman ${ }^{1}$
}

Received: 1 January 2021 / Accepted: 14 June 2021 / Published online: 25 June 2021

(c) The Author(s) 2021

\begin{abstract}
Settling velocity or depositional velocity is considered a key parameter to account for in the drilling technology of oil and gas wells as well as hydrocarbon processing since an accurate estimation of this parameter allows the transport of cuttings efficiently, avoids non-productive time, and helps avoid costly problems. Understanding the settling velocity in fluid with high salinity will help for the better separation of oil and natural gas streams in processing facilities. Although a great amount of effort was given to rheology and settling velocity measurements for power-law fluid and Bingham fluids, there are limited studies available in the literature for Herschel-Bulkley (H-B) fluid with salinity. The present study analyzes the fluid rheology of non-Newtonian fluids with, and without, salinity. Moreover, experiments have been conducted to measure the settling velocity of different diameters of solid particles through Herschel-Bulkley fluids with various salinity conditions. For the rheology analysis, it is found that higher weight percentages of $\mathrm{NaCl}$ lead to low values of shear stresses. As well, higher weight percentages of $\mathrm{CaCl} 2$ concentration result in a slight increase in shear stresses per a given shear rate. On the other hand, higher percentages of salt concentration cause an increase in the terminal velocity.
\end{abstract}

Keywords Herschel-Bulkley fluids $\cdot$ Settling velocity $\cdot$ Rheology $\cdot$ Salinity

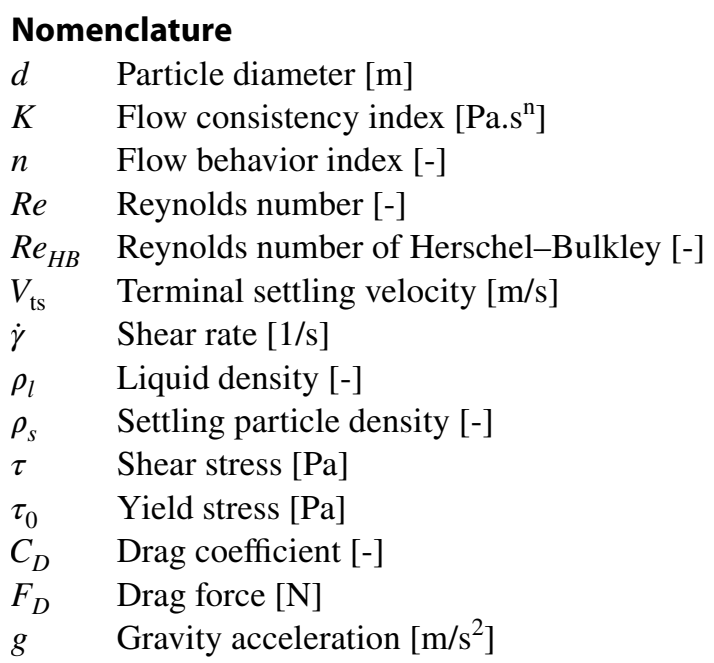

Hicham Ferroudji hichamf32@gmail.com

1 Texas A\&M University at Qatar, Doha, Qatar

\section{Introduction}

\section{Rheology of drilling fluids}

All fluids can be separated into two main rheological categories: Newtonian and non-Newtonian. Newtonian fluids, such as pure water or pure oil, have a direct and linear relationship between shear stress $(\tau)$ and shear rate $(\dot{\gamma})$. Non-Newtonian fluids, however, produce nonlinear relationships. Non-Newtonian fluids can be divided into three main subcategories: viscous fluids, time-dependent fluids, and viscoelastic fluids (Melton and Saunders 1957). Figure 1 demonstrates the respective shear stress $(\tau)$ versus shear rate $(\dot{\gamma})$ relationships (Gucuyener 1983).

For the Herschel-Bulkley model, the following relationship is considered (Hershel and Bulkley 1926):

$$
\tau=\tau_{o}+K(\dot{\gamma})^{n}
$$

where $K$ is the fluid consistency index and $n$ is the behavior index. If the initial yield value $\tau_{o}=0$, the power-law model is obtained (Reiner 1926):

$\tau=K(\dot{\gamma})^{n}$.

Texas A\&M University at Qatar, Doha, Qatar 


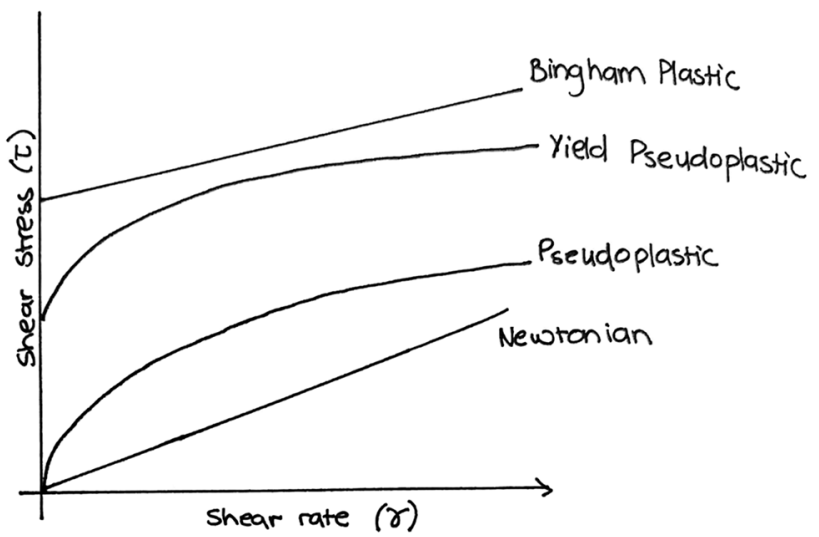

Fig. 1 Typical rheological models of shear stress versus shear rate (Gucuyener 1983)

Table 1 Composition of the studied fluids (Hassiba Amani 2012)

For this model, when the fluid behavior index $(n)$ is below $1(n<1)$, the shear-thinning behavior will take place, while the shear thickening will occur when for $n>1$. Lastly, a fluid with $(n=1)$ results in a Newtonian behavior with an initial yield value, resulting in the Bingham model (Bingham 1922):

$\tau=\tau_{o}+P V(\dot{\gamma})^{1}$

where $P V$ stands for the plastic viscosity.

A paper was published by Hassiba Amani (2012) where the authors studied the effects of salinity on drilling fluids. The authors used two salts, $\mathrm{NaCl}$ and $\mathrm{KCl}$. The composition of the considered fluids is presented in Table 1-

Afterward, concentrations of $3 \mathrm{wt} \%, 5 \mathrm{wt} \%$, and $7 \mathrm{wt} \%$ of each of the two salts were added and studied under different cases: from 0 to $241 \mathrm{MPa}$ (from 0 to $35,000 \mathrm{psi}$ ) and from 21 to $232{ }^{\circ} \mathrm{C}$ (from 70 to $450^{\circ} \mathrm{F}$ ). They observed that the addition of $\mathrm{NaCl}$ increases the shear stress per a given shear rate. It is believed $\mathrm{NaCl}$ has improved the shear-thickening behavior of the fluid. On the other hand, the authors deduced $\mathrm{KCl}$ may enhance the shear-thinning phenomena of the fluid. It can also be seen that HPHT conditions induced a larger range between the different concentrations of salt, indicating that the weight percentage of salt has more influence on the shear stress in bottom hole conditions.

Anawe and Folayan (2019) recently employed a statistical analysis on various types of muds, but more importantly on water-based muds (WBMs). The authors prepared their samples with components and compositions under standard procedures recommended by the American Petroleum Institute. They also applied different rheological models on the datasets obtained from the experiments where the overlaying of all these models with their respective abbreviations is shown in Fig. 2. The Herschel-Bulkley model was found to be the most effective model for predicting the rheology of WBMs because it describes accurately the behavior at low and high shear rates.
Fig. 2 Comparison of various models to the measured experimental data of Anawe and Folayan (2019)

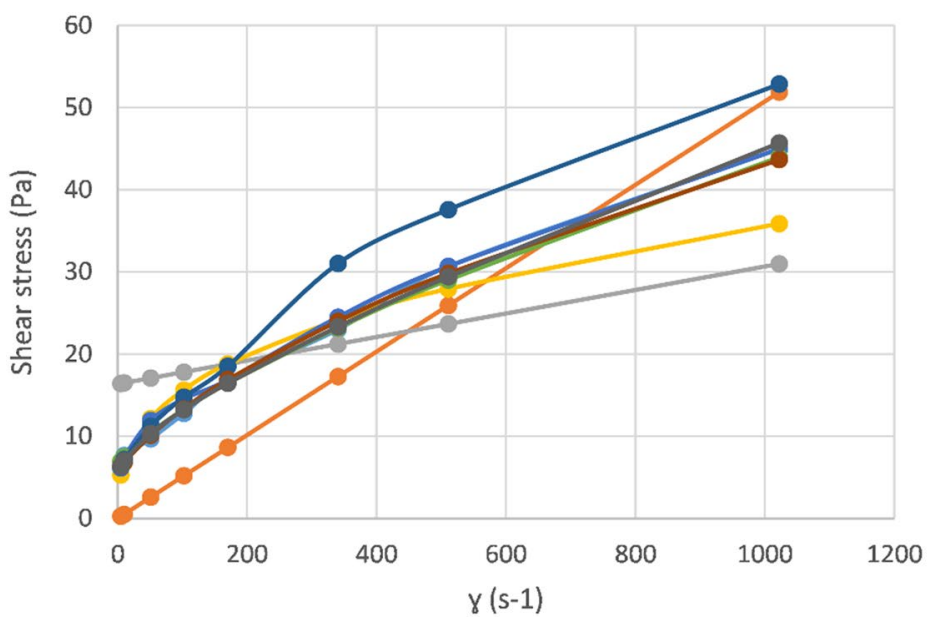




\section{Settling velocity of solid particles}

Settling velocity is the velocity of an object moving in a fluid when the force due to gravity balances the resistive drag force. As the object accelerates and its velocity increases, the drag force acting on the object also increases. The velocity at which the drag force has increased to equal the force of gravity is considered as settling velocity (Winterwerp Kranenburg 2002). Inclusion of solid particles in a liquid phase makes the fluid a multiphase system. Several studies have been performed to understand the fundamental flow dynamics of gas-liquid flow systems (Rahman et al. 2009a, 2009b, Ejim et al. 2010). Similar studies are found for solid-liquid two-phase systems in the literature (Sleiti et al. 2020, Rehman et al. 2018, and Zahid et al. 2020). There are also studies available in the literature for the drilling fluid hydraulics and its relation to well control (Manikonda et al. 2019, Xiong et al. 2016, Ahammad et al. 2018, Amin et al. 2019). There are limited studies available for solid-liquid flow systems in no-circulation conditions. Gas kick and other well control events are prominent during the no-circulation stage and during the connection time when the drilling mud is in stagnant conditions. In stagnant conditions, understanding solid particle hydrodynamics, especially in non-Newtonian fluid, is very important for well construction, drilling mud design, and hole cleaning of the wellbore.

Various industrial applications such as geothermal drilling, water waste processing, and drilling of oil and gas wells require a good knowledge of the terminal settling velocity of solids in a liquid. The settling velocity of a particle through a fluid is dependent on many factors such as particle size, shape, particle grain size, and density of the settling medium. Hazzab et al. (2008) reported on the measurement and modeling of the settling velocity of isometric particles they carried out and where they defined a dimensionless number for the particle properties and flow characteristics.

A study was carried out to understand the effects of changing parameters on the settling process in yield-powerlaw fluids (Baldino et al. 2015). The parameters were varied including the rheological properties, temperature, drilled cuttings properties, and flow conditions. Also, a relationship was derived based on the continuity and Navier-Stokes equations to model the settling velocity for a spherical particle. It was deduced that for non-spherical particles, a spiral trajectory is observed and the particle vibrates as it falls. In another study regarding the settling velocity of particulate systems (Arcil 2009), the author developed a numerical method, which he validated with experimental data. However, the model was limited only to one-dimensional direction.

The drag coefficient can be correlated as a function of different parameters such as sphericity, circularity, and smoothness. In reality, particles are not perfect spheres but irregular
3D objects. It is difficult to determine their parameters using the tools that would be used for a perfect sphere. To simplify these irregular objects, an equivalent diameter can be used instead.

According to the literature, there are few ways that researchers have employed to determine the equivalent diameter of irregular particles. There are two types of diameter that can be used. One is the Feret diameter and the other is the projected area diameter. The difference between the two diameters is presented in Fig. 3. Some techniques that can be used to determine the parameters of the particles are the laser obscuration time (LOT) and the image analysis (AmbiValue 2017).

Campbell and Thurley (2017) employed 3D laser scanning to determine the size of particles in caving mines where the limitations induced by the image analysis method can be avoided. The distribution of fragmented rocks and their sizes can be also determined using this technique.

It was discovered the orientation of the non-spherical particles plays an important role in the value of the drag coefficient. This is because of the surface area on which the drag force is acting on with different orientations. Hence, it is important that this effect should be taken into account when carrying out the experiment. It was concluded that the considered models to determine a particle's shape can induce an error of $30 \%$ when calculating the settling velocity; additionally, particles with high irregularities may result in high errors (Bagheri et al. 2015).

Li et al. (2012) carried out research to determine the sphericity of non-spherical objects. Firstly, they considered spheres with a sphericity of 1.0. The next object they investigated was the lowest a regular tetrahedron with sphericity of 0.671 . The literature provided formulas for different objects to determine their sphericity. For instance, ParticleSizer script software was suggested by many researchers to measure the size and shape. Another method consisted of measuring the volume of the rock by placing it in a container. The equivalent diameter could be calculated based
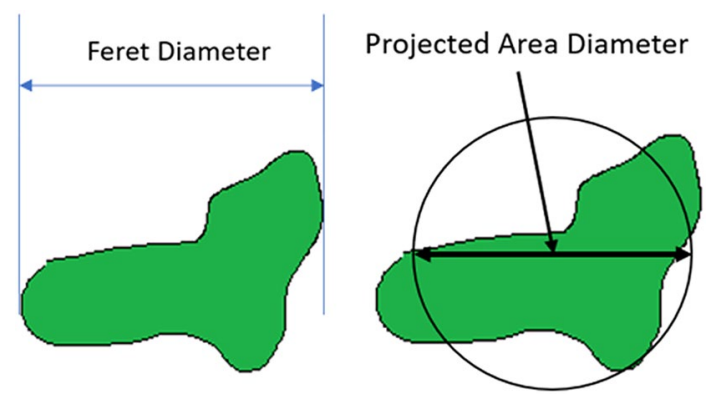

Fig. 3 Examples of Feret and projected area diameter of a particle (AmbiValue 2017) 
on a relationship using the determined volume of the rock (Ma et al. 2014).

Rushd et al. (2019) proposed a modified model of Wilson to overcome its limitations predicting the settling velocity of spherical particles in non-Newtonian fluids where more accurate results were obtained, in particular for the Reynolds number more than 10.

In another experimental work of Mohammed and Halagy (2013), the effects of size and shape of solid particles and rheological characteristics of non-Newtonian fluids (power law) on settling velocity were evaluated using an experimental setup with $1.6 \mathrm{~m}$ of length where the settling velocity of the dropped solid particle is calculated through estimation of falling time. The solid particles consisted of balls and crushed rocks as spheres and irregular shapes, respectively, in which the equivalent spherical diameter was considered to estimate its irregularity. Their investigation led to conclude that the increment in the flow index behavior $(n)$ causes a decrease in the settling velocity. In addition, as the latter diminishes with the concentration of polymers, they also found that the particle diameter increases settling velocity.

Rushd et al. (2021) carried out an investigation of settling velocity of spheres in Newtonian and non-Newtonian fluids employing machine learning algorithms (MLAs) to overcome complex calculation steps, high degree of uncertainty, and iterations of traditional methods of settling velocity prediction. Moreover, to validate the applicability of the model, multiple metrics were considered by the authors including root mean square error (RMSE), mean absolute error (MAE), coefficient of determination $\left(R^{2}\right)$, and meansquared error (MSE).

From the literature, we found that:

- The settling velocity value of solid particles with spherical shape is higher than solid particles with irregular shape due to the additional drag force that can be induced.

- The difference in settling velocity is higher for water than for oil.

- As sphericity increases, the fall velocity of a particle increases.

- For non-spherical particles, the orientation of the particle as it falls affects the settling velocity.

- The rheology of the fluid has a great impact on the settling velocity of the particle.

As few models were found in the literature for settling velocity, the objective of this study is to determine the settling velocity of spherical particles in Herschel-Bulkley fluids and to compare experimental data of the drag coefficient as a function of the Reynolds number with that derived from the Wilson et al. (2003) model. It is also a real possibility that drilling mud may become contaminated by salt layers in the formation being drilled as well as in offshore drilling. For that reason, the effect of salinity on Herschel-Bulkley fluid is evaluated in the present study.

\section{Materials and methods}

\section{Theory}

Determining the time required of a solid to settle down in a non-Newtonian fluid is highly dependent on the shape of the solid; the key parameters have been determined from previous studies including determination of the particle Reynolds number $\left(R_{e}\right)$ and the drag force coefficient $\left(C_{d}\right)$ (Mohammed and Halagy 2013).

The Reynolds number is defined as the ratio of the internal forces experienced on a fluid to the viscous forces. In the case of a stationary fluid, the Reynolds number is mathematically expressed as:

$\operatorname{Re}=\frac{\mathrm{dV}_{\mathrm{ts}} \rho_{l}}{\mu_{l}}$

where $d$ is the diameter of solid, $V_{\mathrm{ts}}$ is the velocity of the particle, $\rho_{l}$ is the density, and $\mu_{l}$ is the viscosity. On the other hand, the drag coefficient is defined as the resistance of an object in a fluid such as water, air, or drilling mud. Mathematically, it is expressed as:

$C_{D}=\frac{4\left(\rho_{s}-\rho_{l}\right) \mathrm{dg}}{3 V_{\mathrm{ts}}^{2} \rho_{l}}$

where $\rho_{s}$ is the solid density and $g$ stands for the gravity.

When a particle reaches the terminal velocity, this means the drag force equalizes the gravity force. The latter is written as (Kelessidis and Mpandelis 2004):

$F_{D}=\frac{\pi}{6} d^{3}\left(\rho_{s}-\rho_{l}\right)$.

It is important to note that Eqs. (4) and (5) are valid in the case of Newtonian fluids (Rushd et al. 2019). In the case of non-Newtonian fluids, these equations should be modified using the appropriate model. In the case of the Herschel-Bulkley model, the relationship between the shear stress and the shear rate is expressed as follows:

$\tau=\tau_{0}+K(\dot{\gamma})^{n}$

where $\tau_{0}$ is the yield stress, $K$ is the consistency index, and $n$ consists of the flow behavior index.

The relationship of Machač et al. (1995) is employed to evaluate the Reynolds number where the apparent viscosity is calculated at a shear rate equals to the ratio of the 
terminal settling velocity $\left(V_{\mathrm{ts}}\right)$ and the particle diameter $(d)$, as follows:

$\operatorname{Re}_{\mathrm{HB}}=\frac{d^{n}\left(V_{\mathrm{ts}}\right)^{2-n} \rho_{l}}{\tau_{0}\left(\frac{d}{V_{\mathrm{ts}}}\right)^{n}+K}$.

Although the Wilson method (Wilson et al. 2003) is an explicit method to determine the terminal velocity, the major drawback of this method is its high uncertainty $(75 \%$ and above) of the predicted values. Through the literature, there are different modified models of the Wilson method proposed to improve the accuracy of results for non-Newtonian fluids. Among these models, the model of Kelessidis and Mpandelis (2004) is written as:

$C_{D}=\frac{24}{\operatorname{Re}_{s}}\left(1+0.1407 \mathrm{Re}_{s}^{0.6018}\right)+\frac{0.2118}{1+0.4215 / \operatorname{Re}_{s}}$.

The drag coefficient for the experimental data was also determined using the following equation (Cheng 2009).

$C_{D}=\frac{24}{\operatorname{Re}}+\frac{4}{\sqrt{\operatorname{Re}}}+0.4, \operatorname{Re}<10^{5}$.

\section{Rheology experimental setup}

The rheological tests were performed on a variety of fluids with different compositions. Table 2 summarizes the sample types based on their weight percentage (wt \%) of different chemical compounds:

All samples were mixed with $500 \mathrm{~mL}$ of water, excluding the corn oil. It was assumed water has a density of

Table 2 Sample concentration variations

\begin{tabular}{llll}
\hline Sample & Flowzan [wt \%] & $\mathrm{NaCl}[\mathrm{wt} \%]$ & $\mathrm{CaCl}_{2}[\mathrm{wt} \%]$ \\
\hline 1 & 0.1 & no salt & no salt \\
2 & 0.2 & no salt & no salt \\
3 & 0.3 & no salt & no salt \\
4 & 0.1 & 3 & no salt \\
5 & 0.1 & 6 & no salt \\
6 & 0.1 & 9 & no salt \\
7 & 0.2 & 3 & no salt \\
8 & 0.2 & 6 & no salt \\
9 & 0.2 & 9 & no salt \\
10 & 0.1 & no salt & 3 \\
11 & 0.1 & no salt & 6 \\
12 & 0.1 & no salt & 9 \\
13 & 0.2 & no salt & 3 \\
14 & 0.2 & no salt & 6 \\
15 & 0.2 & no salt & 9
\end{tabular}

$\rho_{W}=1000 \mathrm{~kg} / \mathrm{m}^{3}$ at ambient conditions to simplify the calculation procedure.

Additionally, it was initially proposed to perform experiments with salts of $3 \mathrm{wt} \%, 6 \mathrm{wt} \%$, and $12 \mathrm{wt} \%$; however, alterations were observed, and it was decided to change this to $3 \mathrm{wt} \%, 6 \mathrm{wt} \%$, and $9 \mathrm{wt} \%$. The observed alteration was because of the high precipitation observed at $12 \mathrm{wt} \%$ for both $\mathrm{NaCl}$ and $\mathrm{CaCl}_{2}$ salts. The precipitation would remain regardless of mixing time. It was possible to eliminate the precipitation by performing experiments at higher temperatures instead of ambient conditions; however, the temperature increase would alter the rheological properties of the fluid (12 wt \%) and thus deem the results independent of the $3 \mathrm{wt} \%$ and $6 \mathrm{wt} \%$ samples. In addition, due to the high opaqueness of the fluids, we cannot raise the salt concentration up to $12 \mathrm{wt} \%$. After consideration, it was reasoned that $9 \mathrm{wt} \%$ would suffice for the purpose of variation of salt concentration. It is worthy to note that there was no precipitation for both salts at $9 \mathrm{wt} \%$ for the $0.1 \%$ Flowzan.

\section{Settling velocity experimental setup}

Initially, experiments were carried out using a Canon DSLR camera, which has 24 frames per second. When the footage was reduced, it was observed that due to the low number of frames, the particle was shown to be stretched out, indicating that it existed simultaneously at different locations in that times, as shown in Fig. 4. The recording was changed with a black and white high-speed camera. For this equipment, it was observed that if the frames per second were increased, the recording would start to be dark. As shown in Fig. 5, more light sources overcame this issue where data could be recorded at 85 frames per second.

The settling velocity was first determined for the fluid $0.1 \mathrm{wt} \%$ Flowzan with sodium chloride $(\mathrm{NaCl})$ of $3 \mathrm{wt} \%$ $(7.500 \mathrm{~g})$. This process was repeated while keeping $0.1 \mathrm{wt} \%$

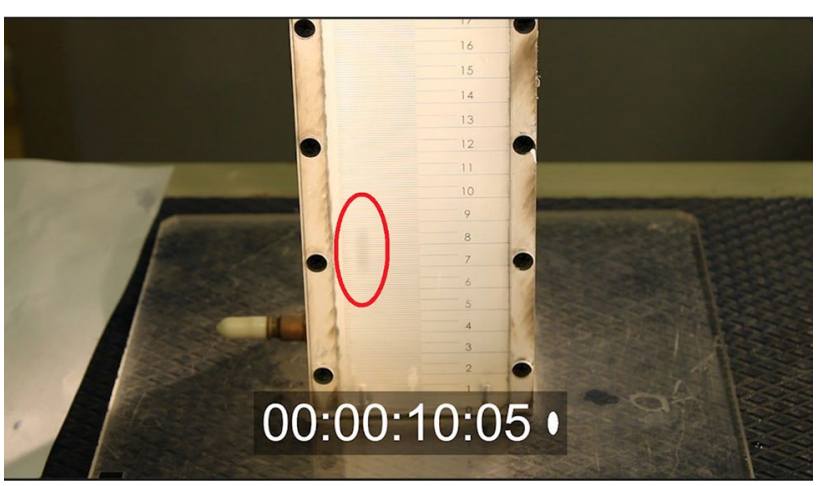

Fig. 424 frames per second with diameter $4.76 \mathrm{~mm}$ glass ball in water 


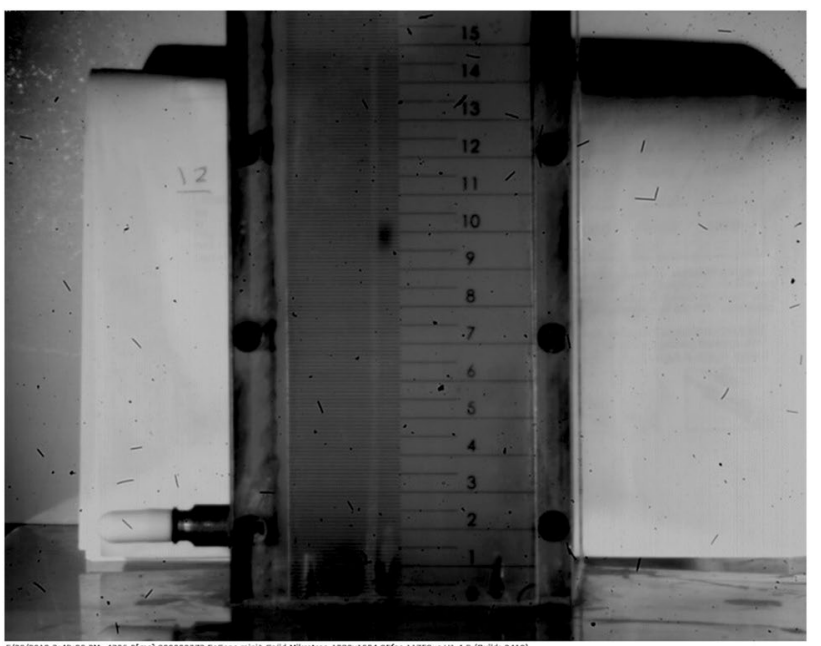

Fig. 5 Snapshot of the spherical particle when recorded with the high-speed camera at $85 \mathrm{fps}$

Flowzan constant and varying the salt concentration $(\mathrm{NaCl})$ to $6 \mathrm{wt} \%$ and $9 \mathrm{wt} \%$. The concentration of the Flowzan was then changed to $0.2 \%$, and the $\mathrm{NaCl}$ salt wt $\%$ was varied again starting from 3\% wt $\%, 6 \% \mathrm{wt} \%$, and $9 \% \mathrm{wt} \%$. Similarly, Flowzan samples were made following the same procedures, but the salt was changed to calcium chloride $\left(\mathrm{CaCl}_{2}\right)$. The variation of $\mathrm{NaCl}$ and $\mathrm{CaCl}_{2}$ concentrations would allow us to understand more about the rheological behavior of Herschel-Bulkley fluids in the presence of salts as well as accurate predictions of the settling velocity of spherical particles in such non-Newtonian fluids.

The mixture with $0.1 \mathrm{wt} \%$ Flowzan with $3 \mathrm{wt} \% \mathrm{NaCl}$ was poured into the column until a height of $60 \mathrm{~cm}$ is reached. Black glass spheres with a diameter of $9.53 \mathrm{~mm}$ and $4.76 \mathrm{~mm}$ were dropped into the column and recorded. Each reading was carried out three times to ensure reliable and repeatable results.

\section{Results and discussion}

\section{Rheology of Newtonian and non-Newtonian fluids}

Corn oil was used to observe the behavior of Newtonian fluids; Fig. 6 presents the relationship of the shear stress versus the shear rate.

It is noted that for all the rheological graphs, curve fitting is used to obtain the necessary trend lines. The purpose of measuring the viscosity of the Newtonian fluid is first to prove that the equipment used is calibrated as well as to ensure that the followed methodology for the experimentation is effective. As presented in Fig. 7, clear differences can be observed between the Newtonian and the Herschel-Bulkley properties.

Contrary to the Newtonian fluid, it is evident that Flowzan mixtures present yield stress in which the higher the concentration of Flowzan, the more viscous it is, thus increasing the yield stress. Moreover, since the curves of the experimental data almost follow the Herschel-Bulkley model described in Eq. 7, the following equation is considered to determine the three parameters of the trend line for all samples, as given in Table 3.

$y=a+b(x)^{c}$
$a$ : Yield stress $\left(\tau_{0}\right)$.
$b$ : Consistency index $(K)$.
$c$ : Behavior index $(n)$.

\section{Effects of $\mathrm{NaCl}$ concentration on rheology behavior}

To assess the effects of $\mathrm{NaCl}$ concentration on fluid rheology, experiments were performed with varying $\mathrm{NaCl}$ concentrations. The results were obtained using the procedures and equipment previously described in Methodology section. Figures 8 and 9 present the data points and curve
Fig. 6 Shear stress vs. shear rate of corn oil

\section{Newtonian Fluid Rheology (Corn Oil)}

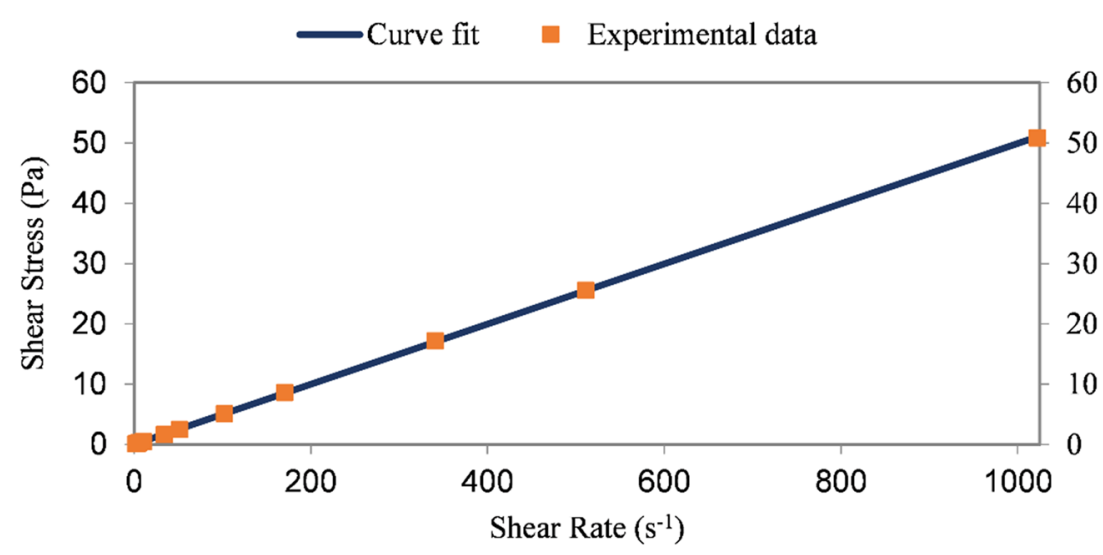


Fig. 7 Rheological behavior of various concentrations of Flowzan

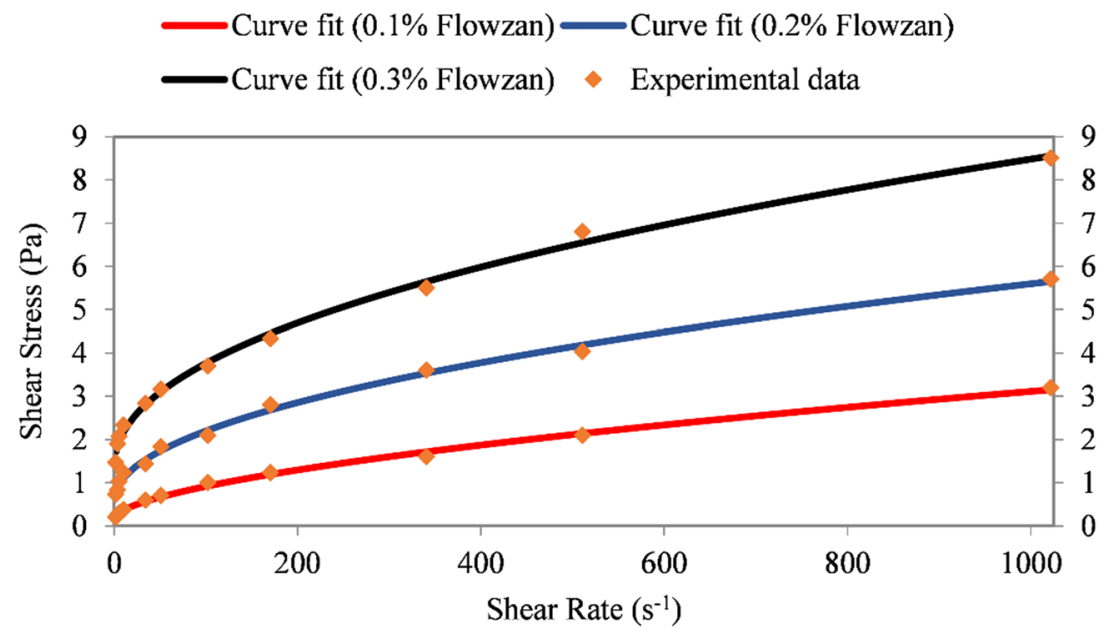

Table 3 Herschel-Bulkley parameters of various concentrations of Flowzan

\begin{tabular}{lllll}
\hline Sample & $K$ & $n$ & $\tau_{0}$ & $\mathrm{R}^{2}$ \\
\hline $0.1 \%$ Flowzan & 0.04 & 0.60 & 0.18 & 0.997 \\
$0.2 \%$ Flowzan & 0.16 & 0.49 & 0.58 & 0.996 \\
$0.3 \%$ Flowzan & 0.27 & 0.47 & 1.36 & 0.996 \\
\hline
\end{tabular}

fits obtained from the experiments. It can be observed from both figures that the increase in $\mathrm{NaCl}$ concentration leads to lower shear stresses for a given shear rate. Additionally, higher $\mathrm{NaCl}$ concentrations seem to lower the yield stress needed for fluid mobility. It is also evident that the $0.2 \%$ Flowzan mixtures exhibit stronger trends toward the Herschel-Bulkley model regardless of the $\mathrm{NaCl}$ concentration indicating that Flowzan is still the primary compound in providing the Herschel-Bulkley fluid characteristics. In other words, even with the increase in $\mathrm{NaCl}$ concentration, the evolution of the shear stress is almost the same, which indicates that the rheological behavior of the sample of $0.2 \%$ Flowzan is slightly affected by the addition of $\mathrm{NaCl}$.

Most importantly, a prevailing trend can be observed in which higher $\mathrm{NaCl}$ concentrations lead to lower shear stresses. This can be attributed to the molecular structure of $\mathrm{Na}$ and $\mathrm{Cl}$ ions upon dissolution where the increase in the concentration of sodium ions in the solution results in a decrease in the repulsive forces, because of the charge screening influence, and the chain coils up which causes a decrease in the hydrodynamic radius of the polymer and thus the viscosity of the polymer solutions diminishes. Higher concentrations may also lead to a decrease in this frictional force, which decreases the shear stress values at any given shear rate.

The addition of $\mathrm{NaCl}$ may be useful if it is desirable to lower the viscosity of the fluid. Additionally, $\mathrm{NaCl}$ may be useful as a mild mud weight increasing agent, in situations where bentonite may not be preferable (e.g., wanting to prevent formation damage for future wireline logging).
Fig. 8 Rheological behavior of $0.1 \mathrm{wt} \%$ Flowzan with various concentrations of $\mathrm{NaCl}$
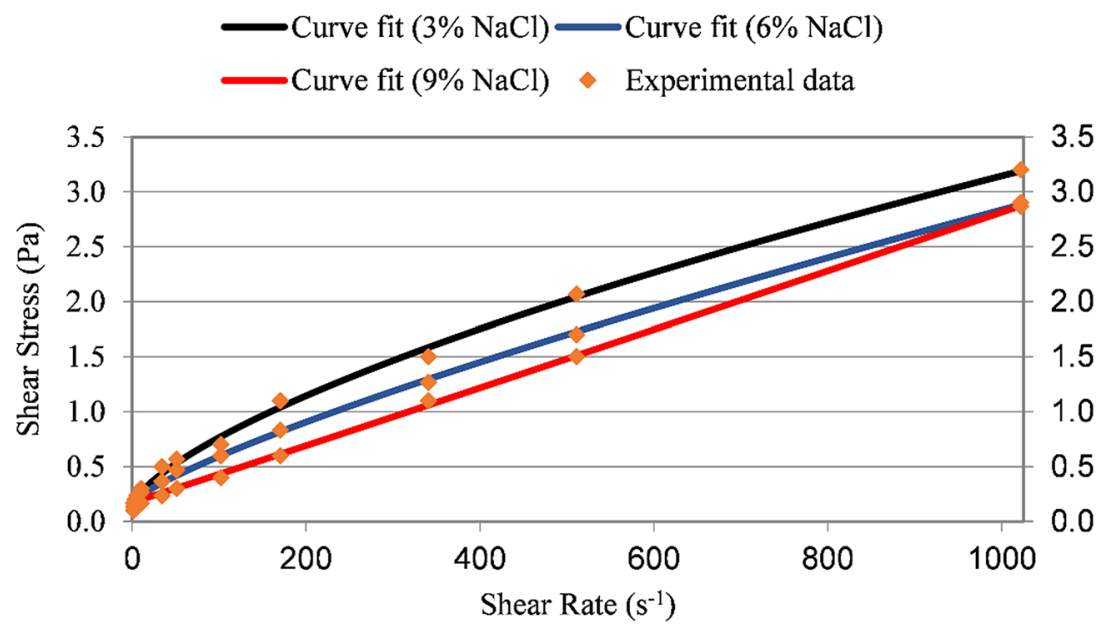


\section{Effects of $\mathrm{CaCl} 2$ concentration on rheology behavior}

Samples from 10 to 15 were mixed and tested following the previously described procedures. Figures 10 and 11 present the plotted results from the $\mathrm{CaCl}_{2}$ experiments with Flowzan concentrations of $0.1 \mathrm{wt} \%$ and $0.2 \mathrm{wt} \%$, respectively. From Fig. 10, a reverse trend occurs for $\mathrm{CaCl}_{2}$ where high concentrations of $\mathrm{CaCl}_{2}$ lead to greater shear stress for a given shear rate. But a slight difference is stated between $6 \mathrm{wt} \%$ and $9 \mathrm{wt} \%$ of $\mathrm{CaCl}_{2}$ concentrations. However, the difference
Fig. 9 Rheological behavior of $0.2 \mathrm{wt} \%$ Flowzan with various concentrations of $\mathrm{NaCl}$

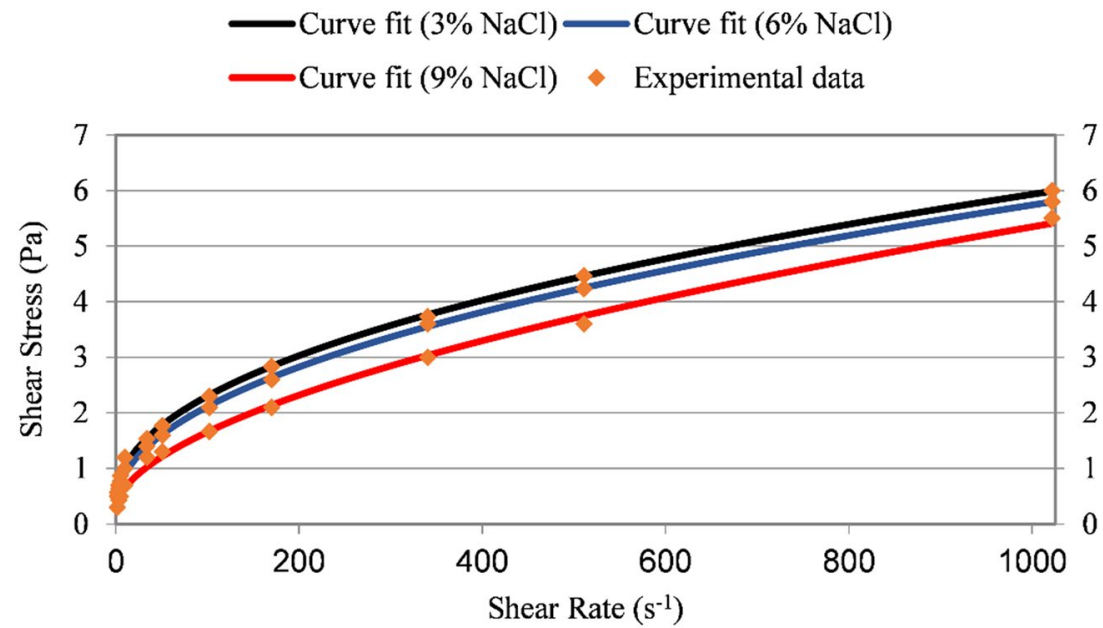

Fig. 10 Rheological behavior of $0.1 \mathrm{wt} \%$ Flowzan with various concentrations of $\mathrm{CaCl}_{2}$

Fig. 11 Rheological behavior of $0.2 \mathrm{wt} \%$ Flowzan with various concentrations of $\mathrm{CaCl}_{2}$
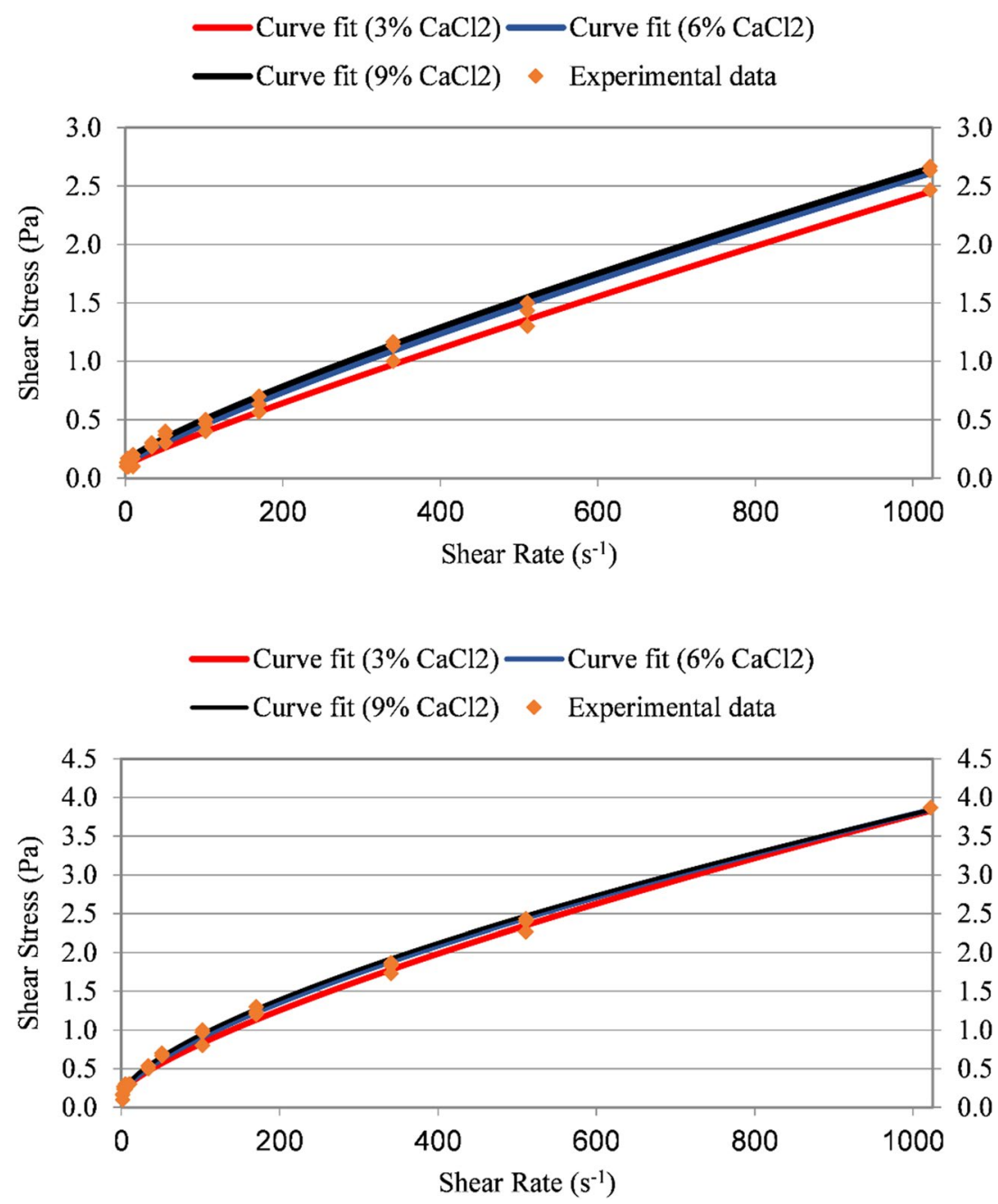
is more evident when the mixtures of $9 \mathrm{wt} \%$ and $3 \mathrm{wt} \%$ are compared. Additionally, it is observed that at $0.1 \%$ Flowzan concentration, the mixed sample behaves more like a Bingham plastic fluid than one of the Herschel-Bulkley models. This indicates that the $\mathrm{CaCl}_{2}$ stunts the effects of Flowzan. Moreover, the shear stress as a function of shear rate for the $0.2 \mathrm{wt} \%$ Flowzan concentration, it is found that the curve follows the Herschel-Bulkley model. Also, it is deduced that there is a marginal effect induced by the change of $\mathrm{CaCl}_{2}$ concentration at $0.2 \%$ Flowzan, indicating that the addition of $\mathrm{CaCl}_{2}$ has a negligible effect on the mud properties.

\section{Settling velocity of solid particles}

The experimentation was first carried out with the Newtonian fluid (water) considering two different diameters of black glass spheres of radius $9.53 \mathrm{~mm}$ and $4.76 \mathrm{~mm}$. Figure 12 shows the instantaneous velocity over time for the 9.53-mm-diameter black glass sphere in water. During the calculation of the instantaneous velocity, the time between the frames is considered to be small as possible to obtain accurate results.
From Fig. 12, it is observed that initially, the sphere enters the water with a high velocity for all three trails. This is due to the fact that the particle is released from the top of the column; hence, it accelerates in the air downward before it hits the water at a certain speed. Then, the velocity is observed to decrease due to an increase in the drag force. Once the velocity of the particle reaches the steady state, it can be considered that the terminal velocity is reached. The data above show signs of repeatability as the different trials overlap each other. The small variations in the data point may be due to the presence of small air bubbles in the fluid.

For the Newtonian fluid (water), the drag coefficient versus the Reynolds number is plotted in Fig. 13. It is observed that there is an exponential decrease in the drag coefficient as the Reynolds number increases where the results from the different trials follow the same trend. This indicates that at high particle Reynolds numbers where inertial forces dominate viscous forces, the drag force displays a decreasing trend till a certain Reynolds number $\left(R_{e}=20000\right)$ where low values of the drag coefficient are reported. Moreover, a similar trend is stated by Song et al. (2017).
Fig. 12 Instantaneous velocity of sphere with diameter of $9.53 \mathrm{~mm}$ in water

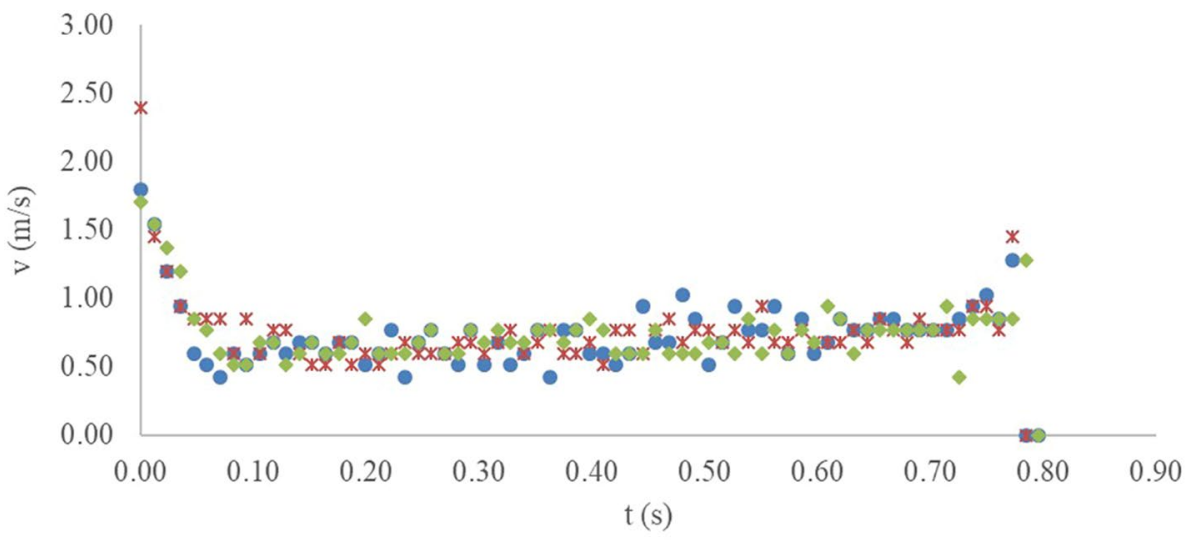

- Trial 1-Inst $*$ Trial 2-Inst $\star$ Trial 3-Inst

Fig. 13 Drag coefficient vs. Reynolds number for the 9.53$\mathrm{mm}$ sphere in water

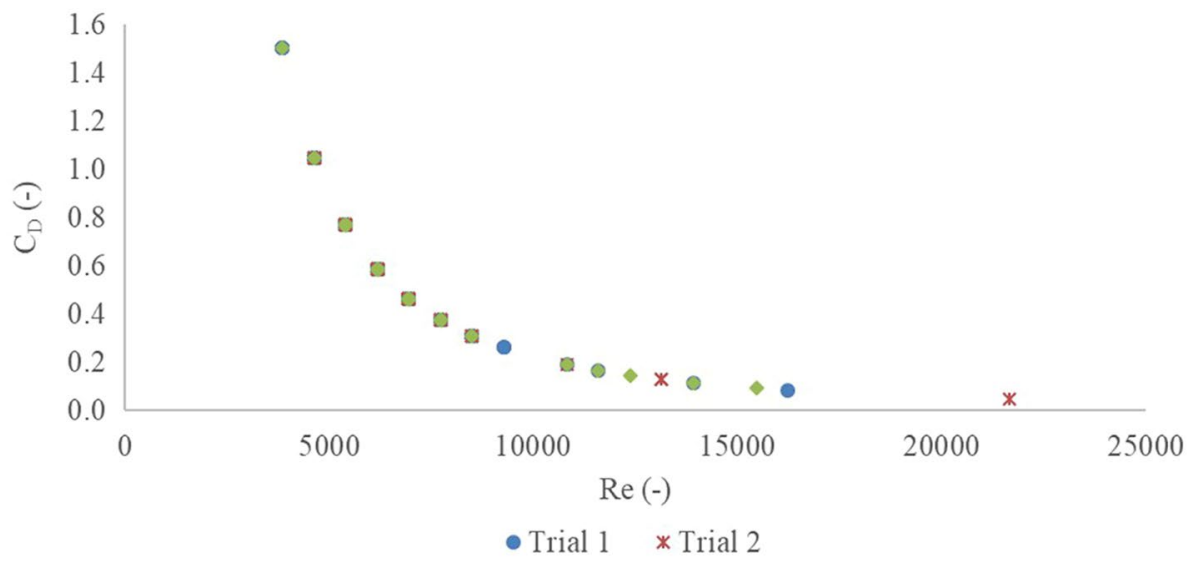


Similarly, the instantaneous velocity is calculated over time for the 4.76-mm black glass sphere (Fig. 14). It is found that the velocity diminishes sharply till a certain terminal velocity. Furthermore, the terminal velocity is stated to be around $0.5 \mathrm{~m} / \mathrm{s}$.

The drag coefficient versus the Reynolds number graph as presented in Fig. 15 exhibits the same exponential decrease as found for the larger diameter sphere where the Reynolds number range was lower for the smaller sphere as compared to the larger one. In addition, the decreasing rate of the smaller particle sphere $(4.76 \mathrm{~mm})$ is higher than that of one of the larger sphere $(9.53 \mathrm{~mm})$ where the lowest values of the drag coefficient are observed from $R_{e}=6000$ of the Reynolds number. This exhibits that at the same Reynolds number, the drag force is important for the bigger particle, especially when the Reynolds number is less than 5000 $\left(R_{e}<6000\right)$. This is evident since the acting forces on the particle that affect the settling velocity are directly related to the particle diameter and particle volume.

For the non-Newtonian behavior, the experimentations are performed with fluids that contain Flowzan and sodium chloride salt. Figure 16 shows the instantaneous velocity of the black glass sphere of $4.76 \mathrm{~mm}$ when dropped in the fluid of $0.1 \mathrm{wt} \%$ Flowzan and $3 \mathrm{wt} \% \mathrm{NaCl}$ fluid in which the observed terminal velocity is approximately $0.43 \mathrm{~m} / \mathrm{s}$. This is lower than the terminal velocity obtained for the same diameter sphere in water. Furthermore, it is observed that for the non-Newtonian fluid of $0.1 \mathrm{wt} \%$ Flowzan with $3 \mathrm{wt} \%$ sodium chloride, the particle reaches the terminal velocity in longer time as compared to the Newtonian fluid (water).

Using the instantaneous velocity obtained as shown in Fig. 16, the Reynolds number was calculated using Eq. 8 . The plot of the drag coefficient versus the Reynolds number for the 4.76-mm sphere in $0.1 \mathrm{wt} \%$ Flowzan and $3 \mathrm{wt} \% \mathrm{NaCl}$ is established by considering the instantaneous velocity from Fig. 16 and using Eq. 8 to determine the Reynolds number, as shown in Fig. 17. From this graph, a power relationship was found between the drag coefficient and the Reynolds number with an $\mathrm{R}^{2}$ value close to 1 , which indicates that the data points fall almost on the trend line.

Figure 18 presents the instantaneous velocity for the fluid with $0.1 \mathrm{wt} \%$ Flowzan and $3 \mathrm{wt} \%$ sodium chloride when a 9.53-mm black glass diameter ball is dropped into the fluid. Comparing the results of this sphere with other diameter
Fig. 14 Instantaneous velocity of sphere with diameter of $4.76 \mathrm{~mm}$ in water

Fig. 15 Drag coefficient vs. Reynolds number for the 4.76$\mathrm{mm}$ sphere in water
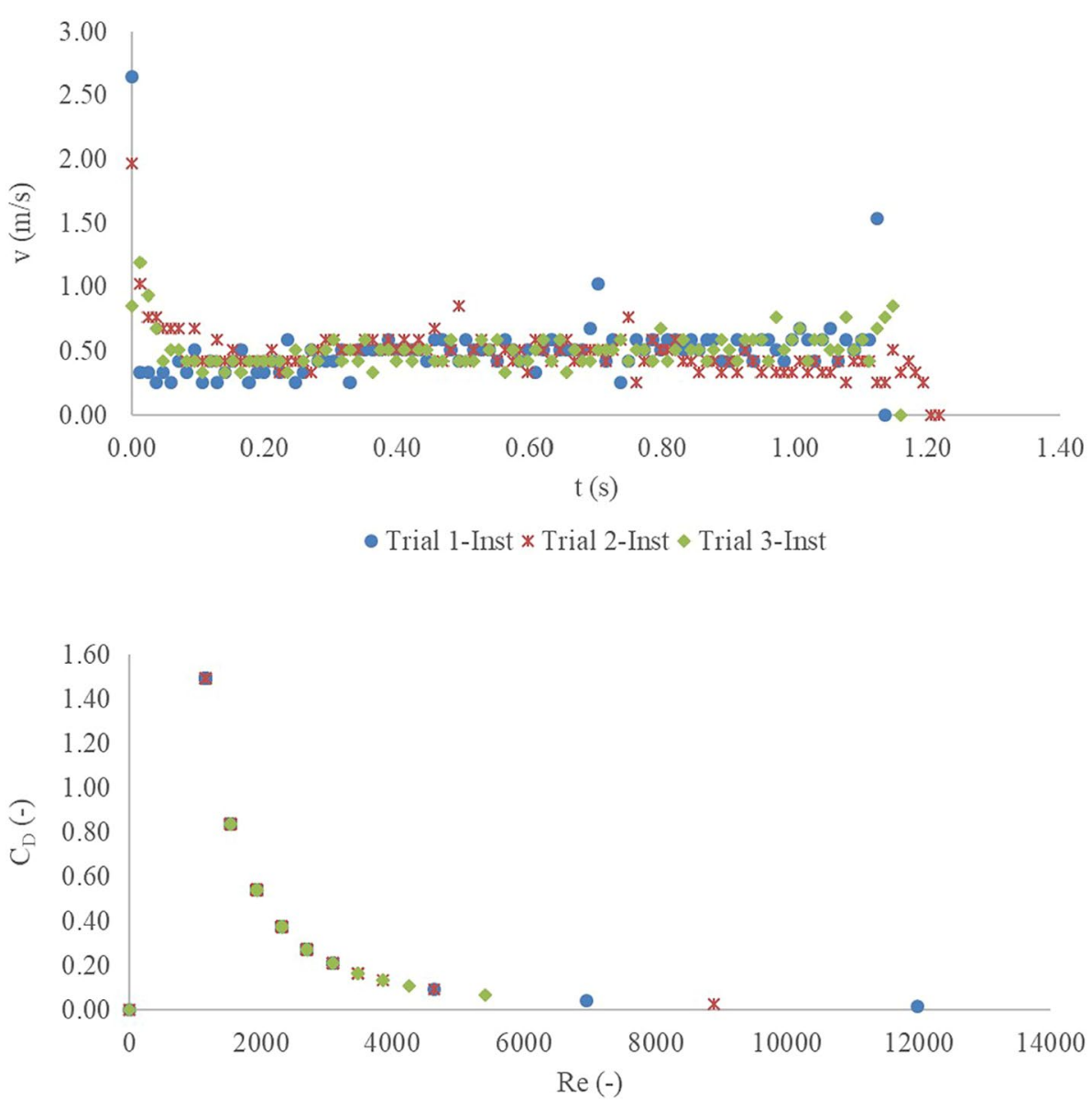

- Trial 1-Inst $*$ Trial 2-Inst $\bullet$ Trial 3-Inst 
Fig. 16 Instantaneous velocity of sphere with diameter of $4.76 \mathrm{~mm}$ in $0.1 \mathrm{wt} \%$ Flowzan with $3 \mathrm{wt} \% \mathrm{NaCl}$

Fig. 17 Drag coefficient vs

Reynolds number for the 4.76$\mathrm{mm}$ sphere in $0.1 \mathrm{wt} \%$ Flowzan with $3 \mathrm{wt} \% \mathrm{NaCl}$

Fig. 18 Instantaneous velocity of sphere with diameter of $9.53 \mathrm{~mm}$ in $0.1 \mathrm{wt} \%$ Flowzan with $3 \mathrm{wt} \% \mathrm{NaCl}$
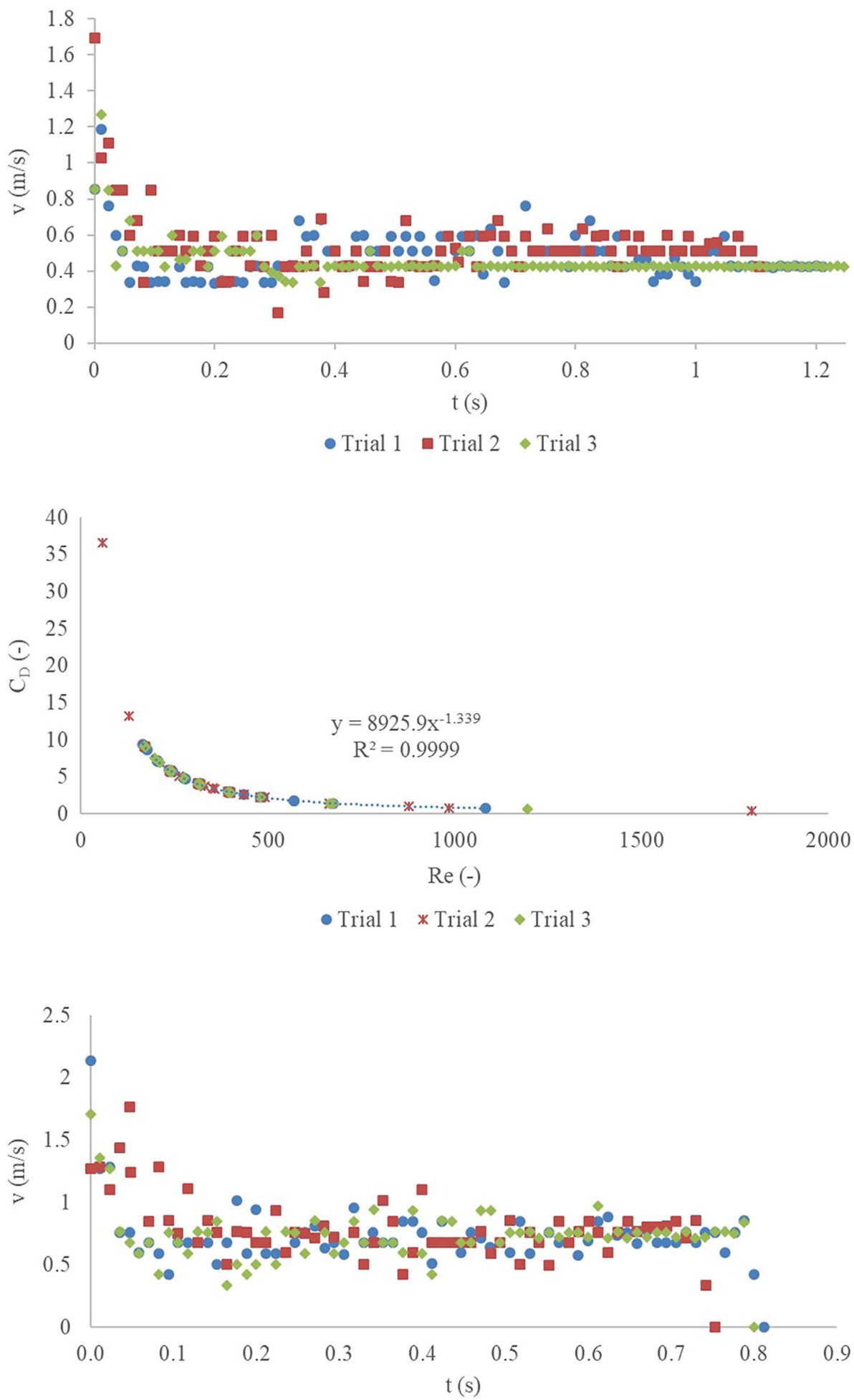

- Trial 1 - Trial 2 spheres, it is observed that there are more variations or fluctuations in the data point for the larger diameter balls. This behavior can be due to the fact that the wall effect is more prominent on such high diameters.
Figure 19 shows the coefficient of drag versus the Reynolds number plot where a power relationship is found between the drag coefficient and the Reynolds number in which the repeatability of experiments is confirmed and 
Fig. 19 Drag coefficient vs. Reynolds number for the 9.53$\mathrm{mm}$ sphere in $0.1 \mathrm{wt} \%$ Flowzan with $3 \mathrm{wt} \% \mathrm{NaCl}$

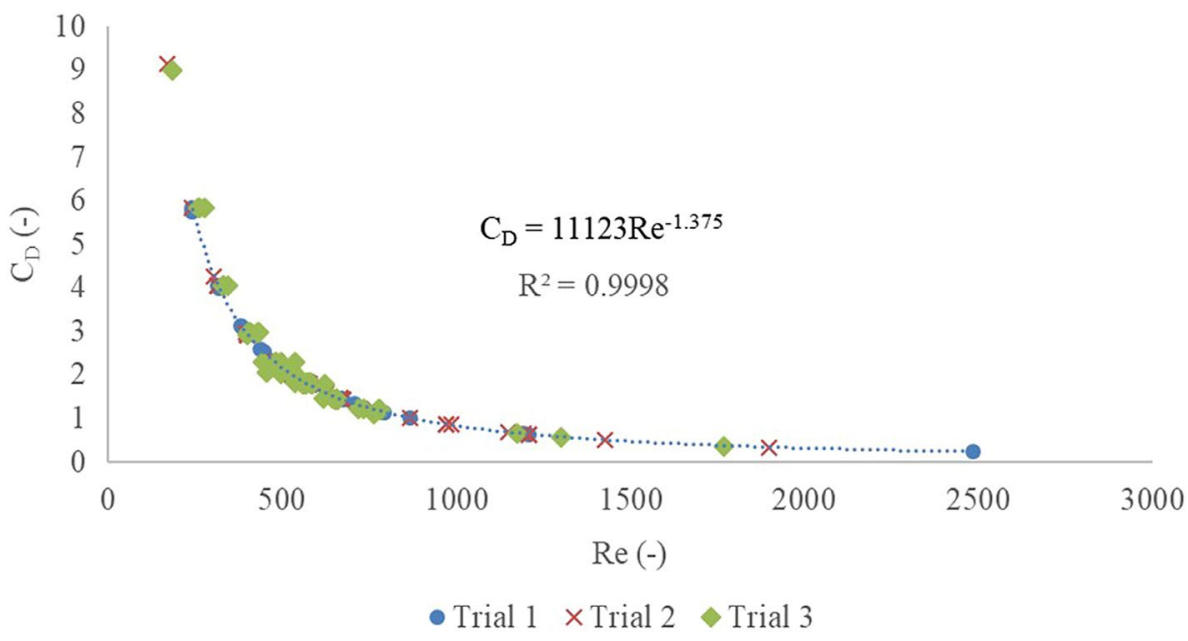

most of the experimental data are situated near to the fit curve.

Figure 20 shows the evolution of the instantaneous velocity of the 4.76-mm sphere in the fluid of $0.1 \mathrm{wt} \%$ Flowzan with $9 \% \mathrm{NaCl}$. Comparing these experimental data of this case with the data obtained from the previous graphs, it is observed that the increase in salt concentration induces a raise of the terminal velocity. Also, this is the case for the 9.53-mm sphere in the same non-Newtonian fluid, as presented in Fig. 21.

To evaluate the effect of sphere diameter on settling velocity, a graph of the terminal velocity as a function of diameter of glass ball is plotted for two different fluids. Figure 22 indicates that the increase in ball diameter causes an increase in the terminal velocity induced by the enhancement in the gravity force. Similarly, with the increase in the salt concentration for the Flowzan fluid, an increase in terminal velocity is observed where the presence of $\mathrm{CaCl}_{2}$ allows to the solid particles to reach higher settling velocities as compared to the $\mathrm{NaCl}$. This can be credited to the effect of salts on the density and viscosity of prepared samples which affects the acting forces on the solid particle (Meng et al. 2012).

\section{Conclusions}

\section{Rheology}

The rheology results can be summarized as follows:

- Higher weight percentages of $\mathrm{NaCl}$ lead to lower shear stresses.

- Higher Flowzan concentrations reduce the impact of $\mathrm{NaCl}$ on the rheology of fluid.

Similar conclusions for the $\mathrm{CaCl}_{2}$ salt can be provided as follows:
Fig. 20 Instantaneous velocity of sphere with a diameter of $4.76 \mathrm{~mm}$ in $0.1 \mathrm{wt} \%$ Flowzan with $9 \mathrm{wt} \% \mathrm{NaCl}$

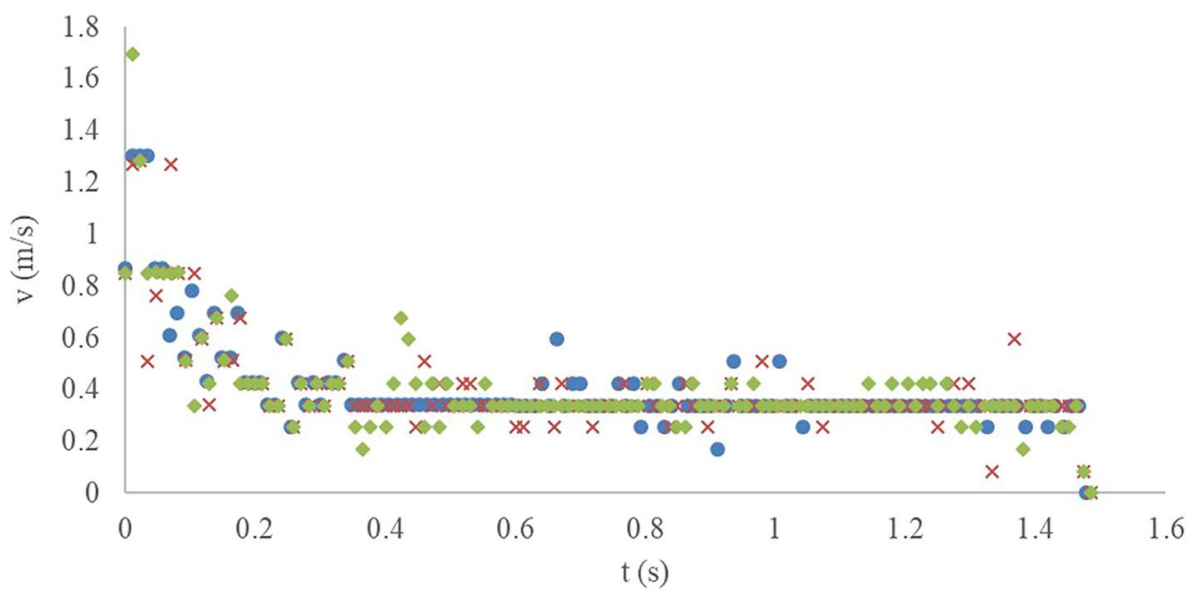

- Trial $1 \times$ Trial 2 
Fig. 21 Instantaneous velocity of sphere with a diameter of $9.53 \mathrm{~mm}$ in $0.1 \mathrm{wt} \%$ Flowzan with 9 wt $\% \mathrm{NaCl}$

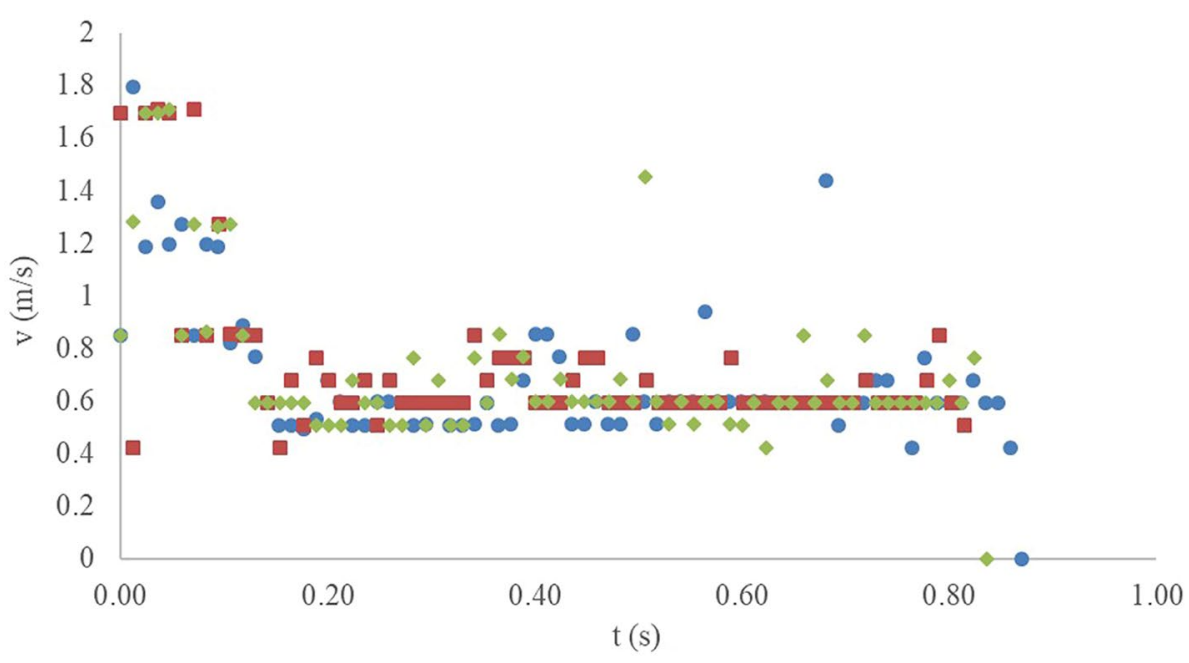

- Trial $1 \backsim$ Trial 2

Fig. 22 Terminal settling velocity vs. sphere diameter for various non-Newtonian fluids
Different Diameter vs. Terminal Velocity of Spheres

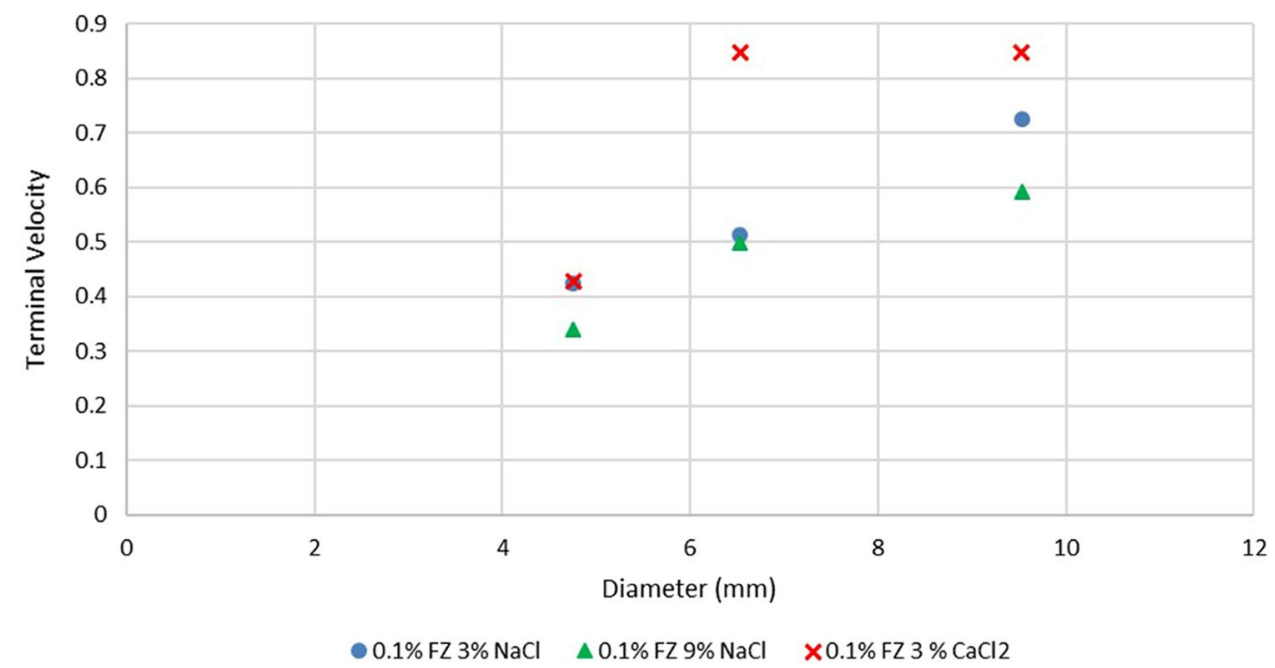

- Higher weight percentages of $\mathrm{CaCl}_{2}$ result in a slight increase in shear stress for a given shear rate.

- Generally, $\mathrm{CaCl}_{2}$ variation results in negligible shear rate variations, regardless of the Flowzan concentration.

- At low Flowzan concentrations $(0.1 \%), \mathrm{CaCl}_{2}$ modifies the rheological model from the Herschel-Bulkley to that of the Bingham plastic model.

The primary takeaway from the experimentation could be summarized in a simple concluding statement: Higher concentrations of $\mathrm{NaCl}$ lead to lower viscosities of WBM, and variation in concentration of $\mathrm{CaCl}_{2}$ can be considered negligible.

Additionally, repetition of the experimentation under higher temperatures would allow testing drilling fluids with even higher salt concentrations to develop a better understanding and allow for a greater range between the weight percentages of salt. This would not be possible under the ambient PT conditions in which the following rheological studies have been performed and precipitate would begin to form at around $12 \mathrm{wt} \%$ for each of the salts, thus ridding the experiments of their validity.

\section{Settling velocity}

From the experimental results, it can be concluded as follows:

- An increase in the diameter of the particle results in an increase in terminal velocity.

- Higher percentages of salt cause an increase in terminal velocity. 
- Power-law relationship was found between the Reynolds number and the drag coefficient for the $0.1 \%$ Flowzan and different sodium chloride percentages.

- Terminal velocity was reached at a longer time for larger diameter balls as compared to the smaller ones.

\begin{abstract}
Acknowledgements The authors gratefully acknowledge the opportunity provided by the Undergraduate Research and Entrepreneurship Program and the financial support of the Qatar National Research Fund in the duration of this research project. The student authors also give great appreciation of Dr. Aziz Rahmin, Dr. Ibrahim Hassan, Dr. Fahed Qureshi, and Dr. Hicham Ferroudji from Texas A\&M University at Qatar for their guidance and wisdom.
\end{abstract}

Funding Undergraduate Research Experience Program (UREP) 23rd Cycle: UREP23-131-2-044.

\section{Declarations}

Conflict of interest On behalf of all the co-authors, the corresponding author states that there is no conflict of interest.

Open Access This article is licensed under a Creative Commons Attribution 4.0 International License, which permits use, sharing, adaptation, distribution and reproduction in any medium or format, as long as you give appropriate credit to the original author(s) and the source, provide a link to the Creative Commons licence, and indicate if changes were made. The images or other third party material in this article are included in the article's Creative Commons licence, unless indicated otherwise in a credit line to the material. If material is not included in the article's Creative Commons licence and your intended use is not permitted by statutory regulation or exceeds the permitted use, you will need to obtain permission directly from the copyright holder. To view a copy of this licence, visit http://creativecommons.org/licenses/by/4.0/.

\section{References}

Ahammad MJ, Rahman MA, Zheng L, Alam JM, Butt SD (2018) Numerical investigation of two-phase fluid flow in a perforation tunnel. J Nat Gas Sci Eng 55:606-611

AmbiValue Application Note, 2017.03 Particle size analysis of nonspherical particles.

Amin A, Imtiaz S, Rahman A, Khan F (2019) Nonlinear model predictive control of a Hammerstein Weiner model based experimental managed pressure drilling setup. ISA Trans 88:225-232

Anawe, Paul \& Folayan, Adewale. (2019). Advances in drilling fluids rheology. Lap Lambert Academic Publishing.

Arcil FC (2009) Settling velocities of particulate systems. Kona Powder Part J 27:18-37

Bagheri G, Bonadonna C, \& Manzella I (2015). Drag Coefficient Of Non-Spherical Particles. EGUGA, 3667.

Baldino S, Osgouei RE, Ozbayoglu E, Miska S, Takach N, May R, and Clapper D (2015) Cuttings settling and slip velocity evaluation in synthetic drilling fluids. In Offshore Mediterranean Conference and Exhibition. Offshore Mediterranean Conference.

Bingham EC (1922) Fluidity and plasticity (Vol. 2). McGraw-Hill.

Campbell AD, Thurley MJ (2017) Application of laser scanning to measure fragmentation in underground mines. Min Technol 126(4):240-247
Cheng NS (2009) Comparison of formulas for drag coefficient and settling velocity of spherical particles. Powder Technol 189(3):395-398

Ejim C, Rahman M, Amirfazli A, Fleck B (2010) Effects of liquid viscosity and surface tension on atomization in two-phase, gas/ liquid fluid coker nozzles. Fuel 89(8):1872-1882

Gucuyener IH (1983) A rheological model for drilling fluids and cement slurries. In Middle East Oil Technical Conference and Exhibition. Society of Petroleum Engineers.

Hassiba KJ, Amani M (2012) The effect of salinity on the rheological properties of water based mud under high pressures and high temperatures for drilling offshore and deep wells. Earth Sci Res 2(1):175-186

Hazzab A, Terfous A, Ghenaim A (2008) Measurement and modeling of the settling velocity of isometric particles. Powder Technol 184(1):105-113

Herschel WH, Bulkley R (1926) Konsistenzmessungen von gummibenzollösungen. Colloid Polym Sci 39(4):291-300

Kelessidis VC, Mpandelis G (2004) Measurements and prediction of terminal velocity of solid spheres falling through stagnant pseudoplastic liquids. Powder Technol 147(1-3):117-125

Li T, Li S, Zhao J, Lu P, Meng L (2012) Sphericities of non-spherical objects. Particuology 10(1):97-104

Ma Y, Lei T, Zhuang X (2014) Volume replacement methods for measuring soil particle density. Trans Chinese Soc Agri Eng 30(15):130-139

Machač I, Ulbrichova I, Elson TP, Cheesman DJ (1995) Fall of spherical particles through non-Newtonian suspensions. Chem Eng Sci 50(20):3323-3327

Manikonda K, Hasan AR, Kaldirim O, Schubert JJ, and Rahman MA (2019) Understanding Gas Kick Behavior in Water and Oil-Based Drilling Fluids. in SPE Kuwait Oil and Gas Show and Conference.

Melton LL, Saunders CD (1957) Rheological Measurements of NonNewtonian Fluids. Trans AIME 210(01):196-201

Meng X, Zhang Y, Zhou F, Chu PK (2012) Effects of carbon ash on rheological properties of water-based drilling fluids. J Pet Sci Eng 100:1-8

Mohammed MA, Halagy DAE (2013) Studying the factors affecting the settling velocity of solid particles in non-Newtonian fluids. Al-Nahrain J Eng Sci 16(1):41-50

Rahman M, Heidrick T, Fleck B (2009) A critical review of twophase gas/liquid industrial spray systems. Int Rev Mech Eng 3(1):110-125

Rahman MA, Mustafiz S, Biazar J, Koksal M, Islam MR (2007) Investigation of a novel perforation technique in petroleum wells- perforation by drilling. J Franklin Inst 344(5):777-789

Rahman MA, McMillan J, Heidrick T, and Fleck BA (2009b) Characterizing the two-phase, air/liquid spray profile using a phasedoppler-particle-analyzer. IOP Journal of Physics-conference series, 147:1-15.

Rehman SR, Zahid AA, Hasan A, Hassan I, Rahman MA, Rushd S (2018) Experimental investigation of volume fraction in an annulus using electrical resistance tomography. SPE J 2019:1-10

Reiner M (1926) Ueber die strömung einer elastischen Flüssigkeit durch eine Kapillare (About the flow of an elastic liquid through a capillary). Kolloid Z 39(1):80-87

Rushd S, Hassan I, Sultan RA, Kelessidis VC, Rahman A, Hasan HS, Hasan A (2019) Terminal settling velocity of a single sphere in drilling fluid. Part Sci Technol 37(8):943-952

Rushd S, Hafsa N, Al-Faiad M, Arifuzzaman M (2021) Modeling the settling velocity of a sphere in Newtonian and non-Newtonian fluids with machine-learning algorithms. Symmetry 13(1):71

Sleiti AK, Takalkar G, El-Naas MH, Hasan AR, Rahman MA (2020) Early gas kick detection in vertical wells via transient multiphase flow modelling: A review. J Nat Gas Sci Eng. https://doi.org/10. 1016/j.jngse.2020.103391 
Song X, Xu Z, Li G, Pang Z, Zhu Z (2017) A new model for predicting drag coefficient and settling velocity of spherical and non-spherical particle in Newtonian fluid. Powder Technol 321:242-250

Wilson KC, Horsley RR, Kealy T, Reizes JA, Horsley M (2003) Direct prediction of fall velocities in non-Newtonian materials. Int J Miner Process 71(1-4):17-30

Winterwerp JC, Kranenburg C (eds) (2002) Fine sediment dynamics in the marine environment. Elsevier

Xiong X, Rahman MA, Zhang Y (2016) RANS based computational fluid dynamics simulation of fully developed turbulent Newtonian flow in concentric annuli. J Fluids Eng 138(9):091202
Zahid AA, ur Rehman SR, Rushd S, Hasan A, Rahman MA (2020) Experimental investigation of multiphase flow behavior in drilling annuli using high speed visualization technique. Front Energy 14(3):635-643

Publisher's Note Springer Nature remains neutral with regard to jurisdictional claims in published maps and institutional affiliations. 